\title{
Approach to delirium in geriatric patients in internal medicine clinics
}

\author{
Bülent Yardımcı \\ Department of Internal Medicine, American Hospital, Istanbul, Turkey
}

\begin{abstract}
Delirium is a life-threatening disease that causes cognitive and attentive disturbance. Contrary to the general belief in internal medicine and surgery clinics, delirium is common among elderly patients, but as its main causes are organic factors, the patients are often undiagnosed or the diagnosis is delayed. In order to prevent problems regarding diagnosis, the internal medicine specialists and the internal medicine department staff should be informed of the situation and raise their awareness of delirium, as early diagnosis increases the success rate of the prevention and treatment of the disease.

Keywords: Delirium, geriatric patient, internal medicine.
\end{abstract}

Delirium is a life-threatening, attention and cognitive function disorder that is common among elderly patients. The term originates from the Latin word de-lira, which means to go out, going mad, and was first used by Celsus in the first century. ${ }^{[1,2]}$

Although the term delirium is known among health professionals, standardization problems in its diagnosis are often overlooked due to the poor knowledge of its precursor symptoms and clinical features. Many times, the diagnosis is made by a neurologist or psychiatrist due to exacerbation of symptoms, and the chance of early treatment is lost.

In this article, we aim to provide essential information regarding delirium to all healthcare professionals, especially internal medicine specialists, working in the internal medicine unit.

\section{TERMINOLOGY}

There are about 30 terms that are synonyms of delirium,,${ }^{[3,4]}$ including: acute brain syndrome, acute organic psychosis, metabolic encephalopathy, acute confusional state, toxic encephalopathy, cerebral insufficiency syndrome, pseudo-senility, toxic confusional state, toxic psychosis, acute organic syndrome, confusion.

Although these terms try to describe an underlying organic or metabolic cause, the terms "delirium" or "confusion" are currently accepted for use.

\section{EPIDEMIOLOGY}

The incidence of delirium in hospitalized patients is reported as 6-56\%.[5] One study reported that delirium was found in $42 \%$ of patients between the ages 70-75, in 58\% of male patients over the age of 76 , and in $67 \%$ of female patients. ${ }^{[6]}$ Although high rates have been reported in postoperative patients, effective diagnosis and treatment is possible in only $32-66 \%$ of patients. ${ }^{[7,8]}$ It should also be kept in mind that delirium is associated with prolonged hospital stay and increased risk of morbidity and mortalit. ${ }^{[9]}$ 


\section{PATHOPHYSIOLOGY}

The pathophysiology of delirium is very complex and still not fully understood. The interaction between changes occurring during an acute disease and its pathophysiology causes an imbalance in brain biochemistry. Although individual predisposing factors, acute illnesses and chemical pathways that cause this may vary, the result is the same: acute brain failure.

In delirium, the balance of neurotransmitters such as acetylcholine, serotonin, gammaaminobutyric acid, and dopamine is disturbed, resulting in patients being unable to process information and provide an appropriate response. Neuronal, dendritic, and microglial damage occurs more easily in elderly patients. ${ }^{[10-12]}$

Factors that play a role in delirium pathophysiology are classified as (i) risk factors and (ii) precipitating factors. These are listed in Table 1. ${ }^{[1]}$

\section{ETIOLOGY}

Many diseases and medical conditions cause delirium. The most common causes are listed in Table 2. ${ }^{[11]} \mathrm{A}$ mnemonic was developed to better remember these etiologies: I WATCH DEATH. ${ }^{[13]}$

\section{WATCH DEATH:}

I : Infection

W: Withdrawal

A : Acute metabolic disorder

$\mathrm{T}$ : Trauma
C : CNS pathology

$\mathrm{H}:$ Hypoxia

D : Deficiencies

E : Endocrinopathies

A : Acute vascular events

$\mathrm{T}:$ Toxins/drugs

$\mathrm{H}:$ Heavy metals

It is important to learn the cause of delirium, since the most important way to eliminate delirium is to correct the underlying cause.

Possible neurological causes of delirium are stroke, encephalitis, meningitis, and ischemic or traumatic brain injury.

Myocardial infarction, heart failure, pulmonary embolism and shock are cardiovascular diseases that cause delirium by causing impaired blood flow and imbalance in oxygenation.

Urinary system infections, pneumonia and sepsis are the most common infections that cause delirium, especially in the elderly.

Elderly people have difficulty emptying their bladder and rectum. The development of sarcopenia, which is the systemic loss of skeleton and smooth muscle, especially contributes to the development of these diseases, and urinary retention and constipation/impaction can lead to delirium in this population.

Pain is also an important cause of delirium. Uncontrolled pain can cause delirium if left untreated. It may be more difficult to detect pain in the elderly due to sensory

Table 1. Factors that play a role in the development of delirium

\begin{tabular}{ll}
\hline Risk factors & Precipitating factors \\
\hline Advanced age & Polypharmacy (5 or more) \\
Cognitive impairment, dementia & Psychoactive or sedative drugs \\
Sensory impairment, hearing and vision loss & Infection \\
Transient ischemic attack, stroke & Surgery or trauma \\
Alcohol dependency & Permanent urinary catheter \\
Major depression & Physical limitation \\
Comorbid diseases & Coma \\
& Physiological/metabolic disorders (abnormal urea/creatinine, $\mathrm{pH}$, \\
\end{tabular}


Table 2. Medical conditions that can lead to delirium

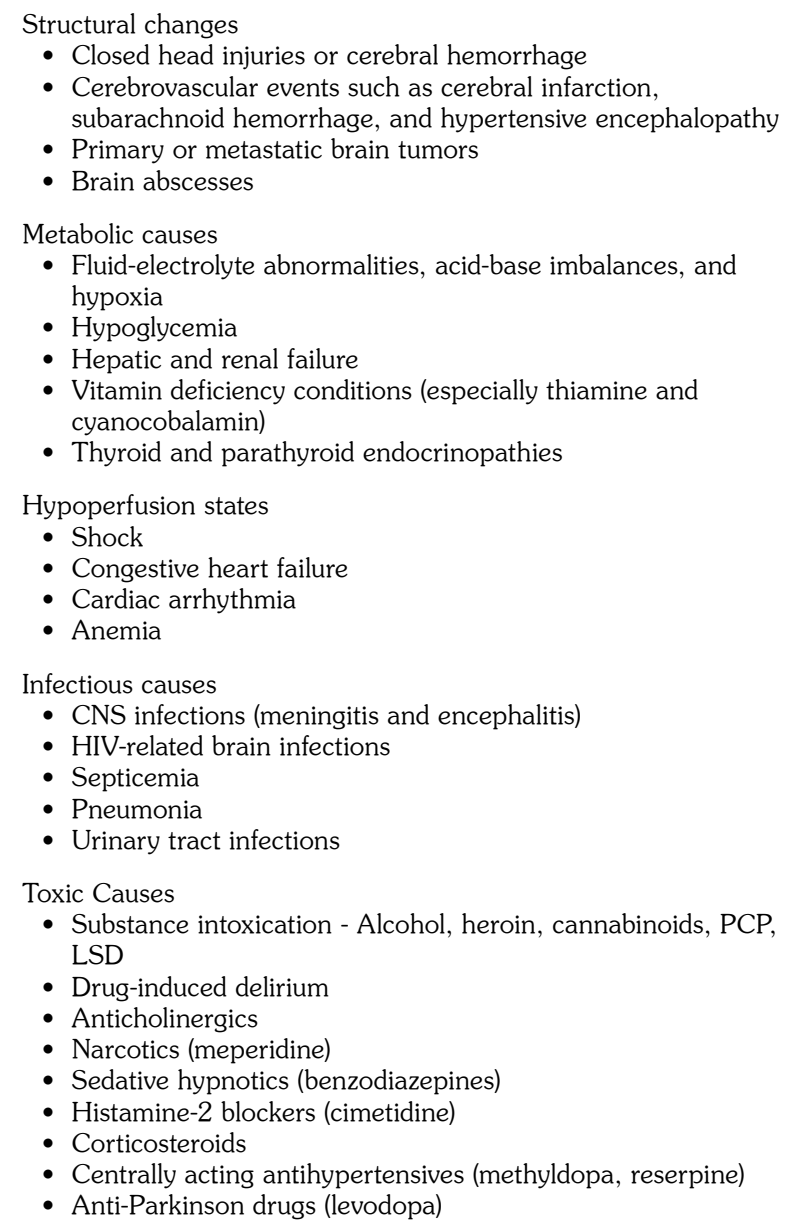

Substance withdrawal associated with alcohol, opioids, and benzodiazepines

CNS: Central nervous system; HIV: Human immmunodeficiency virus; PCP: Phenylcylidine; LSD: Lysergic acid dietylamide.

loss, communication difficulties, and dementia. Since patients with cognitive disabilities cannot reliably express their symptoms of pain, they should be closely monitored for nonverbal pain symptoms.

Drug adverse effects and toxins, including heavy metals, can also cause delirium. Although almost any drug or herbal product can induce delirium, certain classes of drugs have been shown to be more likely to do so. These drugs include anticholinergic drugs, antidopaminergics, antipsychotics, hypnotics, and sedatives. It should be kept in mind that some herbal products and over-the-counter medications can also cause delirium.

\section{CLINICAL PRESENTATION}

Delirium presents with many symptoms and varying severity. Clinical presentation occurs in three different forms: ${ }^{[14-16]}$

1. Hyperactive (agitated, hyperalert): Comprises $30 \%$ of cases. Patients are agitated and experience hallucinations. Disorientation is present. Prognosis is relatively better than other forms. This presentation is common in substance withdrawal.

2. Hypoactive (lethargic, hypo-alert): Comprises $24 \%$ of cases. Agitation is not in the foreground. Patients are mostly tired and confused with reduced level of alertness. Lethargy and catatonic findings may be observed.

3. Mixed type: $46 \%$ of cases. As the name suggests, the patient switches back and forth between periods of agitation and hypoactivity. These changes can develop in a short period of time.

When the patient is initially encountered, prodromal symptoms are important and should be carefully evaluated. Patients are generally tired, easily distracted, and irritable. They are often overly sensitive, irritable, and non-compliant to treatment. They overreact to external stimuli and may describe vivid dreams that they cannot distinguish from reality. ${ }^{[1,2,17]}$

The main symptoms of delirium are confusion, impaired attention, disorientation, disorganized thought and speech, perception disorder, memory disorders, emotional changes, disturbance of the sleep-wake cycle, behavioral changes, and these symptoms generally fluctuate throughout the day. ${ }^{[3,4,6]}$

To illustrate the symptoms with examples:

In the hyperactive state, the patient may have sudden responses to sound or behavior, while patients in the hypoactive state may have difficulty waking up. They may confuse the time, date, month, or where they are. They may say they are at work or home, rather than the hospital. They may be unable to recognize or confuse their relatives. They may be unable to focus their attention on a subject. In brief examination, they may be unable to recite 4-6 nonconsecutive numbers. Speech is 
slurred, they may have difficulty naming objects or understanding conversation. Perception is distorted; they may mistake pipes for snakes, or have illusions and hallucinations such as small imaginary people wandering around the room. Negative thoughts are predominant. They may claim that the nurse administering medication is trying to poison them or that the people around them have negative thoughts of them. When they see their relatives, they may feel overly emotional, cry, or suddenly get angry with the people around them.

\section{DIAGNOSIS}

The Diagnostic and Statistical Manual of Mental Disorders (DSM-5) diagnostic criteria ${ }^{[9]}$ for delirium are as follows:

1. Disturbance in attention (reduced ability to direct, focus, sustain, and shift attention) and awareness (reduced orientation to the environment).

2. The disturbance develops over a short period of time (usually hours to a few days), and tends to fluctuate in severity during the course of the day.

3. An additional disturbance in cognition; memory deficit, disorientation, language, visuospatial ability, or perception
4. These changes cannot be explained by a pre-existing, established or evolving neurocognitive disorder and do not occur in the context of a severely reduced level of arousal such as coma.

5. There is evidence from the history, physical examination or laboratory findings that the disturbance is a direct physiological consequence of another medical condition, substance intoxication or withdrawal (i.e. due to a drug of abuse or to a medication), or exposure to a toxin, or is due to multiple etiologies.

Subsyndromal delirium (SSD) is a more controversial clinical entity than delirium. ${ }^{[18]}$ Although SSD is universally accepted and does not have clearly defined definitive diagnostic criteria, it is listed as "attenuated delirium syndrome" under the subcategory of neurocognitive impairment in DSM-5. Briefly, $\mathrm{SSD}$ is defined as one or more delirium symptoms that do not meet the delirium criteria and do not progress to delirium in elderly people.

Many methods and classifications have been developed to evaluate patients in clinics. Among these are the Confusion Assessment Method (CAM) system CAM-ICU scoring system, Minimental state exam, Ottawa 3DY, and six-item screener. ${ }^{[19-21]}$

Table 3. Confusion assessment method (CAM)

\begin{tabular}{|c|c|}
\hline Feature & Evaluation \\
\hline 1. Acute onset and fluctuating course & $\begin{array}{l}\text { - This feature is usually obtained from a family member or nurse and is shown by positive } \\
\text { responses to the following questions: } \\
\text { - Is there evidence of an acute change in mental status from the patient's baseline? } \\
\text { - Did the (abnormal) behavior fluctuate during the day; that is, did it tend to come and go, or } \\
\text { increase and decrease in severity? }\end{array}$ \\
\hline 2. Inattention & $\begin{array}{l}\text { - This feature is shown by a positive response to the following question: } \\
\text { - Did the patient have difficulty focusing attention; for example, being easily distractible, or having } \\
\text { difficulty keeping track of what was being said? }\end{array}$ \\
\hline 3. Disorganized thinking & $\begin{array}{l}\text { - This feature is shown by a positive response to the following question: } \\
\text { - Was the patient's thinking disorganized or incoherent, such as rambling or irrelevant } \\
\text { conversation, unclear or illogical flow of ideas, or unpredictable switching from subject to } \\
\text { subject? }\end{array}$ \\
\hline 4. Altered level of consciousness & $\begin{array}{l}\text { - This feature is shown by any answer other than "alert" to the following question: } \\
\text { - Overall, how would you rate this patient's level of consciousness? } \\
\text { - Normal: alert } \\
\text { - Vigilant: hyperalert } \\
\text { - Lethargic: drowsy, easily aroused } \\
\text { - Stupor: difficult to arouse } \\
\text { - Coma: unarousable }\end{array}$ \\
\hline
\end{tabular}


The Confusion Assessment Method is summarized in detail in Table 3.

In Ottawa 3DY, the patient is asked the day of the week, the date, to spell the word "world" backwards, and the year.

In the six-item screener, three items are counted (e.g. apple, table, coin) and the patient is asked to recite them. Then the patient is asked the year, month, and day of the week. The patient is then asked to remember the three items.

Although there are many scales and tests for diagnosis, awareness of the DSM- 5 criteria and CAM system will provide the healthcare worker with convenience. Even suspicion of delirium will be helpful to diagnosis. Neurology or Psychiatry specialists may be consulted for complex cases.

One of the most challenging issues for physicians is differentiating between delirium and dementia. When delirium occurs in patients with dementia, the distinction becomes even more challenging. Differentiation between dementia and delirium is presented in Table 4.

Examinations such as ECG, chest X-ray, electrolytes, cardiac enzymes, arterial blood gas, liver enzymes and function tests, ammonia levels, abdominal ultrasound or tomography, TSH, cranial CT, MRI, and lumbar puncture should be performed.

\section{PREVENTING DELIRIUM}

Though not always, delirium is mostly preventable. If the patient has an existing clinical condition that may cause delirium (severe infection, postoperative period, etc.) or if delirium is suspected, general preventive measures should be taken immediately. Disorders that facilitate delirium such as urinary retention, constipation, and pain should be corrected. The patient should be placed in a quiet, well-lit room where he/she is not alone. Nutrition and fluid intake should be well managed and malnutrition should be prevented. Relatives should stay by the patient's side if possible; items to help remember the time and date such as a clock or calendar should be placed near the patient. It is preferred that the patient's bed face a window that gives them a view of the outside. Urinary catheters, signaling monitors, and intravenous therapy should not be applied unless necessary. The IV drip side may block the patient's vision. Excessive sound, light, and emotional stimuli should be avoided. The patient's arms and legs should not be bound to the bed if possible. Working personnel should always introduce themselves and explain what they will do whenever they approach the patient. ${ }^{[21,22]}$

\section{PHARMACOLOGIC TREATMENT OF DELIRIUM}

Delirium treatment should focus on the underlying cause and correct facilitating factors such as dehydration, hypoxia, immobility, infection, polypharmacy, pain, malnutrition, and sleep disorders. While environmental factors and treatment of underlying etiology are the main focus in hypoactive delirium, pharmacologic

Table 4. Differentiating delirium from dementia

\begin{tabular}{lll}
\hline Feature & Delirium & Dementia \\
\hline Onset & Sudden, usually at night & Slow and insidious \\
Duration & Hours, weeks & Months, years \\
Course & $\begin{array}{l}\text { Worse at night, 24-hour fluctuations, periods of } \\
\text { consciousness }\end{array}$ & Progressively worsening \\
Awareness of environment & Always impaired & Generally impaired \\
Orientation & Disoriented time and place & Near and distant memory, decrease in \\
Thinking & Slowed or accelerated imaginary thoughts & Poor abstract thinking \\
Sleep-wake cycle & Always impaired, usually daytime dizziness, & Daytime sleepiness, frequent waking at night \\
& nighttime insomnia & Absent \\
\hline
\end{tabular}


Table 5. Antipsychotic drugs

\begin{tabular}{|c|c|c|c|c|c|}
\hline Drug & Haloperidol & Olanzapine & Quetiapine & Risperidone & Aripiprazole \\
\hline Dosage forms & $\begin{array}{l}\text { Oral tablet } \\
\text { Solution } \\
\text { IM/IV }\end{array}$ & $\begin{array}{l}\text { Oral tablet } \\
\text { Fast-dissolving tablet } \\
\text { IM }\end{array}$ & $\begin{array}{l}\text { Oral tablet } \\
\text { Solution }\end{array}$ & $\begin{array}{l}\text { Oral tablet } \\
\text { Fast-dissolving tablet } \\
\text { Solution }\end{array}$ & $\begin{array}{l}\text { Oral tablet } \\
\text { Fast-dissolving tablet } \\
\text { Solution }\end{array}$ \\
\hline Starting dose & $2 \times 0.5-1 \mathrm{mg}$ & $2 \times 2.5-5 \mathrm{mg}$ & $2 \times 12.5-25 \mathrm{mg}$ & $2 \times 0.5 \mathrm{mg}$ & $2 \times 1$ \\
\hline Half-life (hours) & $12-38$ & $21-54$ & 6 & 20 & 75 \\
\hline Excretion & Hepatic & Hepatic & Hepatic & Hepatic & Hepatic \\
\hline Adverse effects & $\begin{array}{l}\text { Akathisia } \\
\text { Dystonia } \\
\text { Parkinsonism }\end{array}$ & $\begin{array}{l}\text { Akathisia } \\
\text { Parkinsonism }\end{array}$ & Agitation & Parkinsonism & $\begin{array}{l}\text { Akathisia } \\
\text { Agitation }\end{array}$ \\
\hline QTc effects & $\begin{array}{l}\text { Oral and IM: mild } \\
\text { IV: moderate }\end{array}$ & Mild & Mild & Mild & No \\
\hline $\begin{array}{l}\text { Orthostatic } \\
\text { hypotension }\end{array}$ & Mild & Moderate & Severe & Severe & Moderate \\
\hline $\begin{array}{l}\text { Anticholinergic } \\
\text { effect (Dry mouth, } \\
\text { constipation, urinary } \\
\text { retention) }\end{array}$ & Mild & Severe & Moderate & Mild & Mild \\
\hline Sedation & Mild & Moderate & Severe & Moderate & Moderate \\
\hline Other effects & $\begin{array}{l}\text { Minimal effect on } \\
\text { vital signs } \\
\text { May increase } \\
\text { contraction and } \\
\text { motor symptoms in } \\
\text { Parkinson's }\end{array}$ & $\begin{array}{l}\text { Effective in cancer- } \\
\text { related vomiting } \\
\text { Should not } \\
\text { be combined } \\
\text { with parenteral } \\
\text { benzodiazepines, } \\
\text { as it may cause } \\
\text { respiratory } \\
\text { depression }\end{array}$ & $\begin{array}{l}\text { May be preferred in } \\
\text { Parkinson's disease }\end{array}$ & $\begin{array}{l}\text { Has a fast-dissolving } \\
\text { form }\end{array}$ & $\begin{array}{l}\text { May be beneficial in } \\
\text { hypoactive delirium } \\
\text { Unknown effect on } \\
\text { QTc }\end{array}$ \\
\hline
\end{tabular}

IM: Intramuscular; IV: Intravenous.

treatment is especially required in hyperactive and mixed types.

Pharmacologic treatment reduces anxiety and agitation. It prevents the patient from falling and harming themselves and their environment. It also prevents symptoms such as hallucinations, delusions, aggression, and restlessness in hyperactive delirium. ${ }^{[23,24]}$

Haloperidol has long been considered the gold standard drug for the treatment of delirium and is widely used. ${ }^{[25]}$ Second-generation antipsychotics such as quetiapine, risperidone, and olanzapine are used for short-term treatment in patients who can take oral drugs. Physicians should be aware that these drugs may prolong the QT period. The most commonly used drugs in delirium and their usage patterns are summarized in Table 5 .

In general, benzodiazepines should be avoided because these drugs may exacerbate delirium.
They may be used for certain cases such as those with persistent, resistant symptoms, alcohol or benzodiazepine withdrawal, or those with Parkinson's disease, while considering the potential benefit/harm. As with all drug doses in the elderly, benzodiazepine and antipsychotics should be initiated at low doses. ${ }^{[26]}$

\section{Declaration of conflicting interests}

The author declared no conflicts of interest with respect to the authorship and/or publication of this article.

\section{Funding}

The author received no financial support for the research and/or authorship of this article.

\section{REFERENCES}

1. Işıı AT. Geriatrik olgularda deliryum. In: Küçükardalı Y, Terekeci H, editors. Yoğun bakımda yaşlı hasta sorunlar1. 1st ed. İstanbul: Nobel Tip Kitabevleri; 2009. s. 3-8. 
2. Oh ES, Fong TG, Hshieh TT, Inouye SK. Delirium in Older Persons: Advances in Diagnosis and Treatment. JAMA 2017;318:1161-74.

3. Işık AT. Akut mental değişikliği olan hastaya yaklaşım. In: Işık AT, Eker E, editörler. Geriatrik ve geropsikiatrik aciller. 1st ed. İstanbul: Som Kitap; 2009. s. 25-44.

4. Moran FRACP JA, Dorevitch MI. Delirium in the hospitalised elderly. Aust $J$ Hosp Pharm 2001;31:35-40.

5. Siddiqi N, Harrison JK, Clegg A, Teale EA, Young J, Taylor $\mathrm{J}$, et al. Interventions for preventing delirium in hospitalised non-ICU patients. Cochrane Database Syst Rev 2016;3:CD005563.

6. Marcantonio ER. Delirium in Hospitalized Older Adults. N Engl J Med 2017;377:1456-66.

7. Leentjens AF, Diefenbacher A. A survey of delirium guidelines in Europe. $\mathrm{J}$ Psychosom Res 2006;61:123-8.

8. Minden SL, Carbone LA, Barsky A, Borus JF, Fife A, Fricchione GL, et al. Predictors and outcomes of delirium. Gen Hosp Psychiatry 2005;27:209-14.

9. European Delirium Association; American Delirium Society. The DSM-5 criteria, level of arousal and delirium diagnosis: inclusiveness is safer. BMC Med 2014;12:141.

10. Pappa M, Theodosiadis N, Tsounis A, Sarafis P. Pathogenesis and treatment of post-operative cognitive dysfunction. Electron Physician 2017;9:3768-75.

11. Setters B, Solberg LM. Delirium. Prim Care 2017;44:541-59.

12. Arumugam S, El-Menyar A, Al-Hassani A, Strandvik G, Asim M, Mekkodithal A, et al. Delirium in the Intensive Care Unit. J Emerg Trauma Shock 2017;10:37-46.

13. Packard RC. Delirium. Neurologist 2001;7:327-40.

14. Krahne D, Heymann A, Spies C. How to monitor delirium in the ICU and why it is important Clin Eff Nurs 2006;9:269-72.

15. Heymann A, Sander M, Krahne D, Deja M, WeberCarstens S, MacGuill M, et al. Hyperactive delirium and blood glucose control in critically ill patients. J Int Med Res 2007;35:666-77.
16. McCusker J, Cole MG, Voyer P, Monette J, Champoux N, Ciampi A, et al. Six-month outcomes of co-occurring delirium, depression, and dementia in long-term care. J Am Geriatr Soc 2014;62:2296-302.

17. Kukreja D, Günther U, Popp J. Delirium in the elderly: Current problems with increasing geriatric age. Indian J Med Res 2015;142:655-62.

18. Leonard MM, Agar M, Spiller JA, Davis B, Mohamad MM, Meagher DJ, et al. Delirium diagnostic and classification challenges in palliative care: subsyndromal delirium, comorbid delirium-dementia, and psychomotor subtypes. J Pain Symptom Manage 2014;48:199-214.

19. Inouye SK, van Dyck CH, Alessi CA, Balkin S, Siegal AP, Horwitz RI. Clarifying confusion: the confusion assessment method. A new method for detection of delirium. Ann Intern Med 1990;113:941-8.

20. Shi Q, Warren L, Saposnik G, Macdermid JC. Confusion assessment method: a systematic review and meta-analysis of diagnostic accuracy. Neuropsychiatr Dis Treat 2013;9:1359-70.

21. Ollerton RL. Sensitivity of the ottawa 3DY scale for assessment of cognitive impairment of older emergency department patients. Ann Emerg Med 2018;71:152-3.

22. Thom RP, Mock CK, Teslyar P. Delirium in hospitalized patients: Risks and benefits of antipsychotics. Cleve Clin J Med 2017;84:616-22.

23. Marcantonio ER. In the clinic. Delirium. Ann Intern Med 2011;154:ITC6-1, ITC6-2, ITC6-3, ITC6-4, ITC6-5, ITC6-6, ITC6-7, ITC6-8, ITC6-9, ITC6-10, ITC6-11, ITC6-12, ITC6-13, ITC6-14, ITC6-15.

24. Aguirre E. Delirium and hospitalized older adults: a review of nonpharmacologic treatment. J Contin Educ Nurs 2010;41:151-2.

25. Vasilevskis EE, Ely EW. 2013: updates in delirium. Neurohospitalist 2014;4:58-60.

26. Rose L, Agar M, Burry L, Campbell N, Clarke M, Lee $\mathrm{J}$, et al. Reporting of outcomes and outcome measures in studies of interventions to prevent and/or treat delirium in the critically Ill: A systematic review. Crit Care Med 2020;48:e316-e24. 